\title{
FINANSIAL INKLUSI DALAM PERSPEKTIF DEMOGRAFI (Studi Kasus UMKM Kota Medan)
}

\author{
Choms Gary Ganda Tua Sibarani ${ }^{1{ }^{*}}$, Nelly Armayanti' ${ }^{2)}$, Irwansyah ${ }^{3)}$, Joko Suharianto ${ }^{4)}$ \\ ${ }^{1,2,3,4)}$ Fakultas Ekonomi, Universitas Negeri Medan \\ Email: gary.linaker@gmail.com ${ }^{1}$, nelly.armayanti@yahoo.co.id $^{2}$ \\ irwansyahkeefi78@gmail.com $^{3} \underline{\text { djoko@ }}$ unimed.ac.id $^{4}$
}

\begin{abstract}
Penelitian dilakukan untuk mengkaji perbedaan tingkat inklusi keuangan pelaku UMKM Kota Medan dari sisi gender, usia, omset usaha (pendapatan), pendidikan dan lama usaha. Penelitian ini dilakukan pada 126 sampel pelaku UMKM Kota Medan yang diambel secara cluster random sampling. Jenis dan sumber data dalam penelitian ini adalah data primer berskala nominal. Teknik pengumpulan data dilakukan menggunakan angket. Teknik analisis data dalam penelitian ini melalui pendekatan statistik non parametrik menggunakan kruskal wallis test dan mann whitney u test dengan bantuan SPSS versi 24. Hasil penelitian ini menjelaskan bahwa ternyata lama usaha dan omset usaha (pendapatan) memberikan perbedaan yang signifikan pada tingkat inklusi keuangan pelaku UMKM Kota Medan. Sedangkan gender, pendidikan dan usia tidak memberikan perbedaan yang berarti pada tingkat inklusi keuangan pelaku UMKM Kota Medan.
\end{abstract}

Kata Kunci: Inklusi, Keuangan, Demografi. 


\section{PENDAHULUAN}

Inklusi keuangan sangatlah penting bagi setiap negara. Inklusi keuangan mampu memberi dukungan signifikan pada stabilitas keuangan. Sebagai negara berkembang, peran inklusi keuangan sangat penting bagi perbankan dan masyarakat. Selain itu, inklusi keuangan dianggap mampu membantu meningkatkan HDI (Human Development Index) atau peningkatan pengetahuan dan juga harapan hidup masyarakat. Dengan meningkatnya HDI, maka kesenjangan sosial pun turut menurun dan akhirnya pula dapat membantu mengentaskan kemiskinan di masyarakat.

Menurut Bank Indonesia (2014) inklusi keuangan merupakan upaya dalam meniadakan segala bentuk hambatan baik harga maupun non harga, terhadap akses layanan masyarakat dalam memanfaatkan lembaga keuangan formal. Sedangkan menurut Otoritas Jasa Keuangan (2016) mendefinisikan inklusi keuangan adalah ketersediaan akses pada berbagai lembaga, produk dan layanan jasa keuangan sesuai dengan kebutuhan dan kemampuan masyarakat dalam rangka meningkatkan kesejahteraan masyarakat.

Menurut hasil survey yang dilakukan Global Findex (2014) menjelaskan bahwa inklusi keuangan di Indonesia yang diukur berdasarkan tiga indikator utama yakni formal account, formal saving dan formal credit ternyata masih rendah. Berdasarkan Gambar 1.1 persentase masyarakat Indonesia yang memiliki rekening di lembaga keuangan formal sebesar 35,95 persen. Persentase menabung sebesar 26,56 persen dan persentase meminjam dari lembaga keuangan formal sebesar 13,3 persen. Angka ini masih lebih rendah jika dibandingkan dengan negaranegara di ASEAN seperti Singapura, Malaysia, dan Thailand.

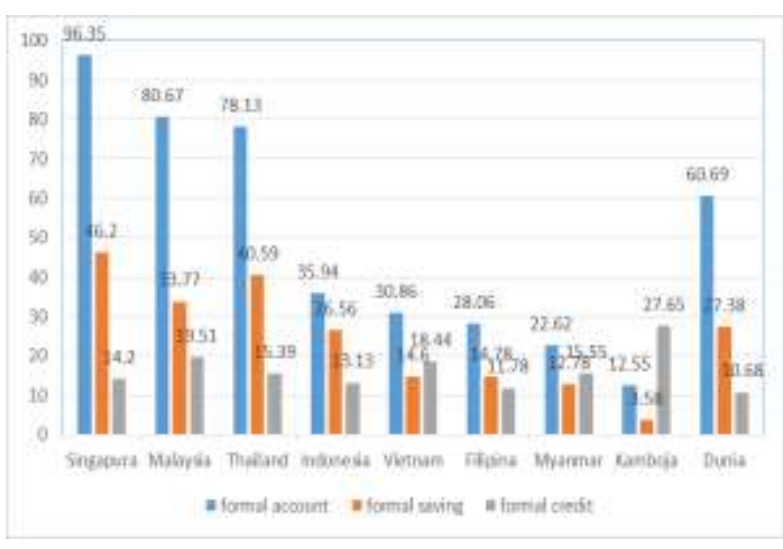

Sumber: Global Findex, 2014

\section{Gambar 1. Inklusi Keuangan Negara ASEAN}

Pengetahuan tentang literasi keuangan ini penting untuk meningkatkan inklusi keuangan. Menurut Hilgert, Hogart, Beverly (2003) menyatakan bahwa mengetahui dan memanfaatkan kredit, tabungan, dan investasi
NIAGAWAN Vol 8 No 3 November 2019 digolongkan memiliki pengetahuan keuangan dan pengalaman keuangan, sehingga peningkatan pengetahuan dan pengalaman keuangan dapat memperbaiki pengelolaan keuangan.

Tingkat inklusi keuangan seseorang tentunya dipengaruhi beberapa faktor, salah satunya fakto demografi. Berdasarkan penelitian terdahulu oleh Wachira dan Kihiu (dalam Nasution et al, 2013) tentang pengaruh literasi keuangan terhadap akses jasa keuangan di Kenya tahun 2009 disimpulkan bahwa akses jasa keuangan tidak hanya dipengaruhi oleh tingkat literasi keuangan. Tingkat pendapatan, jarak dari bank, usia, status perkawinan, jenis kelamin, ukuran rumah rangga, dan tingkat pendidikan memiliki pengaruh yang besar terhadap keputusan mengakses jasa keuangan (inklusi keuangan).

Selain peneliti di atas, beberapa penelitian terdahulu pernah mengkaji tentang sisi demografi terhadap inklusi keuangan masyarakat diantaranya, Clamara et al (2014), Krishnakumar dan Vijayakumar (2013), Hutabarat (2018) meneliti sosio demografi dari sisi gender, usia, pendidikan, pendapatan, pekerjaan dan kependudukan.

Berdasarkan permasalahan, studi empiris dan pendapat ahli di atas, peneliti tertarik untuk mengkaji perbedaan tingkat inklusi keuangan pelaku UMKM Kota Medan ditinjau dari sisi demografi yakni gender, usia, pendidikan, pendapatan (omset), dan lama usaha. Pemilihan subjek penelitian UMKM didasarkan pada besarnya peran perekonomian dan jumlah pelaku UMKM secara umum dan secara khusus di Kota Medan.

\section{TINJAUAN PUSTAKA}

Teori mengenai inklusi keuangan bisa dirujuk dari Irving Fisher (1867-1947) dalam bukunya The Purchasing Power of Money (1911) mengemukakan teori kuantitas sederhana terkait uang. Menurutnya, dalam meningkatkan output ekonomi suatu bangsa yang terpenting bukan saja jumlah uang (Money Supply) melainkan juga kecepatan beredarnya (Velocity of Circulation). Dari hal ini dapat diartikan kecepatan beredarnya uang dalam suatu Negara dimungkinkan jika tingkat inklusi keuangan masyarakatnya sudah semakin tinggi.

Selain itu, Greenwood dan Jovanic (1990) menjelaskan sebuah teori terkait hubungan antara pembangunan pada sektor keuangan dengan distribusi pendapatan. Pada tahap awal pembangunan, pertumbuhan perekonomian lamban. Seiring dengan kenaikan tingkat pendapatan, sektor keuangan semakin 
berkembang sehingga struktur keuangan menjadi lebih luas, pertumbuhan ekonomi semakin cepat, dan ketimpangan pendapatan semakin besar. Pada tahap maturity, perekonomian memiliki struktur keuangan yang sepenuhnya telah berkembang, mencapai distribusi pendapatan yang stabil antar orang, dan memiliki tingkat pertumbuhan yang lebih tinggi dari tahap awal. Berdasarkan teori tersebut, saat ini perkembangan sektor keuangan, khususnya perbankan, di Indonesia dimungkinkan masih berada pada tahap pertumbuhan. Artinya, sektor perbankan semakin berkembang, pertumbuhan ekonomi di Indonesia semakin cepat, dan ketimpangan pendapatan antara orang kaya dengan orang miskin semakin besar.

Beberapa peneliti sebelumnya pernah mengkaji sosio demografi terhadap inkluasi keuangan, diantaranya Hutabarat (2018) menyimpulkan gender, usia, pendidikan dan pekerjaan berpengaruh signifikan, sedangkan pendapatan tidak berpengaruh signifikan terhadap inklusi keuangan. Clamara et al (2014) menyimpulkan usia, gender, pendidikan dan tingkat pendapatan berpengaruh signifikan terhadap inklusi keuangan. Krishnakumar dan Vijayakumar (2013) menyimpulkan bahwa gender, usia, kependudukan dan kualifikasi pendidikan berpengaruh signifikan terhadap tingkat inklusi keuangan masyarakat.

\section{METODE PENELITIAN}

Penelitian ini mengkaji perbandingan tingkat inklusi keuangan dari sisi demografi. Penelitian ini dilaksanakan pada bulan September s.d. Oktober tahun 2019. Populasi penelitian ini adalah seluruh UMKM yang ada di Kota Medan. Sedangkan yang menjadi sampel dalam penelitian ini adalah 126 responden UMKM yang diambil secara cluster sampling dari 21 kecamatan di Kota Medan. Variabel terikat yang digunakan adalah iklusi keuangan, sedangkan variabel bebas adalah sisi demografis yakni gender, usia, lama usaha, omset usaha dan pendidikan. Untuk jenis kelamin dibedakan menjadi 2 kelompok yakni laki-laki dan perempuan. Untuk usia responden dibedakan menjadi 4 kelompok yakni $<25$ tahun; $>25-40$ tahun; > $40-55$ tahun, dan $>55$ tahun. Untuk lama usaha responden dibedakan menjadi 4 kelompok yakni < 3 tahun; $3-5$ tahun; $>5-10$ tahun; dan $>10$ tahun. Untuk pendidikan dibagi menjadi 2 kelompok yakni $\leq \mathrm{SMA}$ dan $\geq \mathrm{PT}$.

Pengumpulan data dilakukan dengan survei dan wawancara mendalam dengan pelaku UMKM. Penelitian ini menggunakan kuesioner inklusi keuangan yang diadopsi dari buku Survei Nasional Literasi dan Inklusi Keuangan 2016 yang dikeluarkan oleh pihak OJK.
NIAGAWAN Vol 8 No 3 November 2019

Data yang dihasilkan dalam penelitian ini adalah berskala nominal. Penelitian ini menggunakan analisis perbandingan berdasarkan kelompok sisi demografis pelaku usaha UMKM. Analisis data dilakukan dengan menggunakan pendekatan statistik non parametric yakni Kruskal Wallis Test untuk variabel usia, omset penjualan, lama usaha dan pendidikan dan Mann-Whitney U Test untuk variabel jenis kelamin. Adapun yang menjadi kriteria dalam uji hipotesis ini adalah Ho diterima jika nilai $p$-value $<0,05$ dan $\mathrm{Ho}$ ditolak jika $p$ value $>0,05$.

Adapun bentuk hipotesis dalam penelitian ini sebagai berikut :

Ho : Tidak terdapat perbedaan tingkat inklusi keuangan pelaku UMKM Kota Medan dari sisi gender, usia, lama usaha, omset usaha, dan pendidikan.

$\mathrm{Ha}$ : Terdapat perbedaan signifikan tingkat inklusi keuangan pelaku UMKM Kota Medan dari sisi gender, usia, lama usaha, omset usaha (pendapatan), dan pendidikan.

\section{HASIL DAN PEMBAHASAN}

Hipotesis 1 : Terdapat perbedaan tingkat inklusi keuangan dari sisi gender pada pelaku UMKM Kota Medan.

Adapun sebaran responden berdasarkan sisi gender pelaku UMKM di Kota Medan sebagai berikut:

Tabel 1. Diskriptif Statistik Responden Dari Sisi Gender

\begin{tabular}{l|lr|r|r}
\multicolumn{5}{c}{ Ranks } \\
\multicolumn{1}{c}{ Gender } & N & $\begin{array}{c}\text { Mean } \\
\text { Rank }\end{array}$ & $\begin{array}{c}\text { Sum of } \\
\text { Ranks }\end{array}$ \\
\hline Inklusi & Laki-laki & 67 & 68.16 & 4566.50 \\
\cline { 2 - 5 } Keuangan & Perempuan & 59 & 58.21 & 3434.50 \\
\cline { 2 - 5 } & Total & 126 & & \\
\hline
\end{tabular}

Sumber : Data Primer (diolah, 2019)

Berdasarkan Tabel di atas diketahui bahwa responden laki-laki berjumlah 67 dan perempan sebanyak 59. Adapun hasil pengujian hipotesis untuk sisi gender adalah sebagai berikut :

Tabel 2. Hasil Uji Hipotesis 1

\begin{tabular}{lr}
\multicolumn{2}{c}{ Test Statistics $^{\mathbf{a}}$} \\
Inklusi Keuangan \\
\hline Mann-Whitney U & 1664.500 \\
\hline Wilcoxon W & 3434.500 \\
\hline Z & -1.562 \\
\hline Asymp. Sig. (2-tailed) & $\mathbf{. 1 1 8}$ \\
\hline a. Grouping Variable: Gender & \\
Sumber : Data Primer (diolah, 2019)
\end{tabular}

Berdasarkan Tabel di atas, diketahui bahwa nilai Sig. 0,118>0,05, maka Ho diterima. Artinya tidak terdapat perbedaan tingkat inklusi keuangan dari sisi gender pada pelaku UMKM Kota Medan. 
Hasil penelitian ini bertentangan dengan penelitian sebelumnya, Clamara et al (2014), Krishnakumar dan Vijayakumar (2013), Hutabarat (2018) menyatakan bahwa gender berpengaruh signifikan terhadap inklusi keuangan.

Namun hasil penelitian ini mendukung peneliti sebelumnya, Nugroho (2017) menemukan bahwa jenis kelamin (gender) tidak berpengaruh terhadap keputusan dalam kepemilikan rekening, menabung dan meminjam di lembaga keuangan formal (inklusi keuangan).

Hal ini menjelaskan bahwa inklusi keuangan masyarakat berjenis laki-laki tidak lebih baik daripada perempuan. Tingkat partisipasi wanita dalam bekerja dan menggunakan produk keuangan sudah semakin meningkat seiring dengan peningkatan finansial teknologi, kemudahan berbisnis dan berbelanja secara online dimasyarakat. Hal ini bertentangan dengan pendapat Chen dan Volpe (2002) juga meneliti bahwa wanita kurang percaya diri dan kurang tertarik untuk belajar tentang pengetahuan keuangan (financial literacy) dibandingkan dengan laki-laki.

Hipotesis 2 : Terdapat perbedaan tingkat inklusi keuangan dari sisi pendidikan pada pelaku UMKM Kota Medan.

Adapun sebaran responden berdasarkan sisi pendidikan pelaku UMKM di Kota Medan sebagai berikut:

Tabel 3. Diskriptif Statistik Responden Dari Sisi Pendidikan

\begin{tabular}{|l|lr|r|r}
\hline \multirow{4}{*}{ Ranks } \\
& Pendididkan_Rev & $N$ & Rank & $\begin{array}{c}\text { Sum of } \\
\text { Ranks }\end{array}$ \\
\hline \multirow{2}{*}{$\begin{array}{l}\text { Inklusi } \\
\text { Keuangan }\end{array}$} & $<=$ SMA & 88 & 63.36 & 5576.00 \\
\cline { 2 - 6 } & $>=$ PT & 38 & 63.82 & 2425.00 \\
\cline { 2 - 5 } & Total & 126 & & \\
\hline
\end{tabular}

Sumber : Data Primer (diolah, 2019)

Berdasarkan Tabel di atas diketahui bahwa responden pendidikan $\leq$ SMA sebanyak 88 orang dan $\geq$ perguruan tinggi sebanyak 38 orang. Adapun hasil pengujian hipotesis untuk sisi pendidikan adalah sebagai berikut :

Tabel 4. Hasil Uji Hipotesis 2

\begin{tabular}{lr}
\multicolumn{2}{c}{ Test Statistics $^{\text {a }}$} \\
Inklusi Keuangan \\
\hline Mann-Whitney U & 1660.000 \\
\hline Wilcoxon W & 5576.000 \\
\hline Z & -.065 \\
\hline Asymp. Sig. (2-tailed) & .948 \\
\hline a. Grouping Variable: Pendididkan_Rev & \\
Sumber : Data Primer (diolah, 2019)
\end{tabular}

Berdasarkan Tabel di atas, diketahui bahwa nilai Sig. 0,948 > 0,05, maka Ho diterima. Artinya tidak terdapat perbedaan tingkat inklusi
NIAGAWAN Vol 8 No 3 November 2019 keuangan dari sisi pendidikan pada pelaku UMKM Kota Medan.

Hasil penelitian ini bertentangan dengan penelitian sebelumnya, Clamara et al (2014) Hutabarat (2018), Nugroho (2017) menyatakan bahwa pendidikan berpengaruh signifikan terhadap inklusi keuangan.

Dari hasil ini dapat dijelaskan bahwa semakin tinggi tingkat pendidikan belum tentu diikuti dengan semakin meningkatnya inklusi keuangan seseorang. Idealnya semakin tinggi pendidikan terakhir, maka semakin luas sumber wawasan dan edukasi keuangannya. Edukasi keuangan yang baik akan meningkatkan pengetahuan dan kesadaran masyarakat mengenai lembaga keuangan formal, produk dan jasa keuangan termasuk fitur, manfaat dan risiko, biaya, hak dan kewajiban, serta untuk meningkatkan keterampilan masyarakat dalam perencanaan dan pengelolaan keuangan.

Namun pada kenyataanya wawasan pengetahuan tentang keuangan tidak merata pada seluruh mahasiswa. Hanya mahasiswa yang memiliki latar belakang jurusan ekonomi saja yang memiliki tingkat pengetahuan keuangan yang lebih baik. Hal ini sesuai dengan hasil peneliti sebelumnya Hal ini sesuai dengan hasil penelitian yang dilakukan oleh Krishna, A. (2010) menjelaskan bahwa tingkat literasi keuangan mahasiswa dengan latar belakang jurusan ekonomi lebih tinggi daripada mahasiswa jurusan non-ekonomi atau eksakta.

Hal ini tentunya perlu mendapat perhatian dari lembaga pendidikan khususnya perguruan tinggi. Menurut Cude (2006) menyebutkan bahwa pendidikan keuangan juga penting karena keputusan keuangan mahasiswa sangat berperan penting untuk kondisi keuangan mereka selama masa kuliah dan bahkan berpengaruh pada kehidupan mereka setelah lulus kuliah.

Hipotesis 3 : Terdapat perbedaan tingkat inklusi keuangan dari sisi lama usaha pada pelaku UMKM Kota Medan.

Adapun sebaran responden berdasarkan sisi lama usaha pelaku UMKM di Kota Medan sebagai berikut:

Tabel 5. Diskriptif Statistik Responden Dari Sisi Lama Usaha

\begin{tabular}{|l|lr|r}
\multicolumn{3}{c}{ Ranks } & \\
\hline & Umur_Usaha & $N$ & Mean Rank \\
\hline \multirow{3}{*}{ Inklusi Keuangan } & $<3$ th & 35 & 54.01 \\
\cline { 2 - 4 } & 3 th -5 th & 46 & 58.59 \\
\cline { 2 - 4 } & $>5$ th -10 th & 27 & 72.83 \\
\cline { 2 - 4 } & $>10$ th & 18 & 80.50 \\
\cline { 2 - 4 } & Total & 126 & \\
\hline
\end{tabular}

Sumber : Data Primer (diolah, 2019)

Berdasarkan Tabel di atas diketahui bahwa responden lama usaha $<3$ tahun sebanyak 35 
orang; 3 tahun -5 tahun sebanyak 46 orang; > 5 tahun - 10 tahun sebanyak 27 orang dan $>10$ tahun sebanyak 18 orang. Adapun hasil pengujian hipotesis untuk sisi lama usaha adalah sebagai berikut :

Tabel 6. Hasil Uji Hipotesis 3

\begin{tabular}{|c|c|}
\hline \multicolumn{2}{|c|}{$\begin{array}{l}\text { Test Statistics } \\
\text { Inklusi Keuangan }\end{array}$} \\
\hline Chi-Square & 9.295 \\
\hline Df & 3 \\
\hline Asymp. Sig. & .026 \\
\hline
\end{tabular}

Sumber : Data Primer (diolah, 2019)

Berdasarkan Tabel di atas, diketahui bahwa nilai Sig. 0,026 < 0,05, maka Ho ditolak. Artinya terdapat perbedaan tingkat inklusi keuangan secara signifikan dari sisi lama usaha pada pelaku UMKM Kota Medan.

Hasil penelitian ini mendukung penelitian sebelumnya, Bonita dan Setiawinna (2017) menyimpulkan bahwa lama usaha berpengaruh signifikan terhadap literasi keuangan.

Literasi keuangan dianggap faktor yang representatif untuk membantu menjelaskan tingkat inklusi keuangan. Hal ini didasarkan pada seseorang akan memiliki produk keuangan jika telah memiliki pengetahuan dan manfaat tentang produk keuangan tersebut.

Hal ini sejalan dengan pendapat Foster dan Karen (2001) menyatakan bahwa lama waktu atau masa kerja, tingkat pengetahuan dan keterampilan yang dimiliki, penguasaan terhadap pekerjaan dan peralatan merupakan beberapa hal yang menentukan seseorang berpengalaman atau tidak dalam bekerja.

Lama usaha memberikan perbedaan yang berarti pada tingkat inkluasi keuangan. Artinya semakin lama rentang waktu usaha yang telah dijalankan seorang pelaku usaha, maka orang tersebut akan semakin ahli dalam menyusun strategi kerja termasuk soal pengelolaan keuangan dan produk keuangan.

Hipotesis 4 : Terdapat perbedaan tingkat inklusi keuangan dari sisi omset pada pelaku UMKM Kota Medan.

Adapun sebaran responden berdasarkan sisi omset pelaku UMKM di Kota Medan sebagai berikut:

Tabel 7. Diskriptif Statistik Responden Dari Sisi Omset Usaha (Pendapatan)

\begin{tabular}{l|lr|r}
\multicolumn{3}{l}{ Ranks } & \\
\hline & Omset & $\mathrm{N}$ & Mean Rank \\
\hline Inklusi & $<10 \mathrm{jt} / \mathrm{bln}$ & 90 & 57.92 \\
\cline { 2 - 4 } Keuangan & $>10-25 \mathrm{jt} / \mathrm{bln}$ & 31 & 78.55 \\
\cline { 2 - 4 } & $>25-100 \mathrm{jt} / \mathrm{bln}$ & 5 & 70.70 \\
\cline { 2 - 4 } & Total & 126 & \\
\hline
\end{tabular}

Sumber : Data Primer (diolah, 2019)
NIAGAWAN Vol 8 No 3 November 2019

Berdasarkan Tabel di atas diketahui bahwa responden omset penjualan atau pendapatan $<10$ juta/bulan sebanyak 90 orang; $>10$ juta -25 juta/bulan sebanyak 31 orang; > 25 juta -100 juta/bulan sebanyak 5 orang. Adapun hasil pengujian hipotesis untuk sisi omset penjualan adalah sebagai berikut :

Tabel 8. Hasil Uji Hipotesis 4

\begin{tabular}{lr}
\multicolumn{2}{|c}{$\begin{array}{r}\text { Test Statistics } \\
\text { Inklusi Keuangan }\end{array}$} \\
\hline Chi-Square & 7.934 \\
\hline Df & .019 \\
\hline Asymp. Sig. & \\
\hline a. Kruskal Wallis Test & \\
b. Grouping Variable: Omset \\
Sumber : Data Primer (diolah, 2019)
\end{tabular}

Berdasarkan Tabel di atas, diketahui bahwa nilai Sig. 0,019 < 0,05, maka Ho ditolak. Artinya terdapat perbedaan tingkat inklusi keuangan secara signifikan dari sisi omset usaha pada pelaku UMKM Kota Medan.

Hasil penelitian ini sejalan dengan penelitian sebelumnya, Clamara et al (2014) menyatakan bahwa omset usaha (pendapatan) berpengaruh signifikan terhadap inklusi keuangan. Hasil ini juga sejalan dengan penelitian sebelumnya, Nugroho (2017), Putro dan Nainggolan (2016) bahwa (omset) pendapatan berpengaruh signifikan terhadap memengaruhi kepemilikan rekening dan menabung di lembaga formal dan inklusi responden dalam memutuskan penggunan layanan produk dan jasa investasi.

Namun hasil penelitian ini bertentangan dengan penelitian sebelumnya, Hutabarat (2018) menyatakan bahwa omset usaha (pendapatan) tidak berpengaruh terhadap inklusi keuangan.

Hal ini menguatkan bahwa tingkat omset atau pendapatan usaha akan meningkatkan kebutuhan dan perhatian para pelaku UMKM untuk mengelola keuangan dengan lebih baik. Salah satunya dengan menggunakan produk keuangan.

Hipotesis 5 : Terdapat perbedaan tingkat inklusi keuangan dari sisi usia pelaku UMKM Kota Medan.

Adapun sebaran responden berdasarkan sisi usia pelaku UMKM di Kota Medan sebagai berikut:

Tabel 9. Diskriptif Statistik Responden Dari Sisi Usia

\begin{tabular}{|c|c|c|c|}
\hline \multicolumn{4}{|c|}{ Ranks } \\
\hline & Usia & $\mathrm{N}$ & Mean Rank \\
\hline \multirow[t]{5}{*}{ Inklusi Keuangan } & $<25$ th & 22 & 52.61 \\
\hline & $>25$ th -40 th & 54 & 62.71 \\
\hline & $>40$ th -55 th & 41 & 67.37 \\
\hline & $>55$ th & 9 & 77.22 \\
\hline & Total & 126 & \\
\hline
\end{tabular}

Sumber : Data Primer (diolah, 2019)

Berdasarkan Tabel di atas diketahui bahwa responden usia $<25$ tahun sebanyak 22 orang; 
usia 25 tahun - 40 tahun sebanyak 54 orang; usia > 40 tahun - 55 tahun sebanyak 41 orang dan $>55$ tahun sebanyak 9 orang. Adapun hasil pengujian hipotesis untuk sisi lama usaha adalah sebagai berikut :

Tabel 10. Hasil Uji Hipotesis 5

\begin{tabular}{lr}
\multicolumn{2}{|c}{ Test Statistics } \\
\multicolumn{2}{c}{ Inklusi Keuangan } \\
\hline Chi-Square & 3.893 \\
\hline Df & 3 \\
\hline Asymp. Sig. & .273 \\
\hline a. Kruskal Wallis Test \\
b. Grouping Variable: Usia \\
Sumber : Data Primer (diolah, 2019)
\end{tabular}

Berdasarkan Tabel di atas, diketahui bahwa nilai Sig. 0,273>0,05, maka Ho diterima. Artinya tidak terdapat perbedaan tingkat inklusi keuangan dari sisi usia pada pelaku UMKM Kota Medan.

Hasil penelitian ini bertentangan dengan penelitian sebelumnya, Clamara et al (2014), Krishnakumar dan Vijayakumar (2013), Hutabarat (2018) menyatakan bahwa usia berpengaruh signifikan terhadap inklusi keuangan.

Hasil ini juga tidak sejalan dengan penelitian sebelumnya, Nugroho (2017) yang menemukan bahwa usia dan pendidikan secara signifikan memengaruhi kepemilikan rekening dan menabung di lembaga formal. Penelitian oleh Putro dan Nainggolan (2016) juga menemukan bahwa pendidikan terakhir berkorelasi serta berpengaruh terhadap inklusi responden dalam memutuskan penggunan layanan produk dan jasa investasi.

Keterbukaan teknologi dan informasi, membuat kehidupan mayarakat saat ini sulit dipisahkan dari gadget dan internet disegala lapisan usia masyarakat. Begitu banyak informasi keuangan dan produk keuangan yang ditawarkan atau diiklan. Keterbukaan informasi ini bisa menyeragamkan kebutuhan atau kepemilikan tentang produk inklusi keuangan yang digunakan.

\section{KESIMPULAN DAN SARAN}

Adapun kesimpulan dalam penelitian ini adalah ternyata umur usaha dan omset usaha (pendapatan) memberikan perbedaan yang berarti pada tingkat inklusi keuangan pelaku UMKM Kota Medan. Sedangkan gender, pendidikan dan usia tidak memberikan perbedaan yang berarti pada tingkat inklusi keuangan pelaku UMKM Kota Medan.

Untuk meningkatkan inklusi keuangan masyarakat perlu dengan cara meningkatkan pengetahuan keuangan melalui jenjang pendidikan khususnya pada level perguruan tinggi. Hendaknya pengetahuan keuangan
NIAGAWAN Vol 8 No 3 November 2019 menjadi prioritas untuk dikembangkan secara bersama tidak hanya kepada mahasiswa jurusan ekonomi semata, melainkan disemua jurusan.

\section{REFERENSI}

Bank Indonesia. 2014. Booklet Keuangan Inklusif. Jakarta (ID): Bank Indonesia.

Bonita, APA dan Setiawina, N.D. 2017. Analisis Determinan Tingkat Literasi Keuangan Pedagang Pada Pasar Tradisional Di Kota Denpasar. E-Jurnal EP Unud, 7[2]: 354380.

Clamara et al. 2014. Factors that Matter for Financial Inclusion: Evidence from Peru. Working Paper No. 14/09.

Chen, H., \& Volpe, R. P. 2002. Gender differences in personal financial literacy among college students. Financial Services Review, 11, 289-307.

Cude, e. (2006). College Students and Financial Literacy: What They Know and What We Need to Learn. Eastern Family Economics and Resource Management Association, 102-108.

Foster, B.S., dan R. Karen. 2001. Pembinaan Untuk Meningkatkan Kinerja Karyawan. Jakarta:PPM.

Greenwood J. and Jovanovic B. (1990). Financial development, growth, and the distribution of income. $\mathrm{J}$ Pol Econ. 98(5):076-107.

Hilgert, M. A., Hogarth, J. M., \& Beverly, S. G. 2003. Household financial management: The connection between knowledge and behavior. Household Saving: Does Financial Education Work? Social Security Bulletin, 72(2), 309-322.

Hutabarat, F. 2018. Pengaruh Literasi Keuangan dan Financial Technology Terhadap Inkluasi Keuangan Pada Masyarakat Jabodetabek. Skripsi dipublikasi. Bogor : IPB.

Khrisna, A. (2010). Analisis Tingkat Literasi Keuangan di Kalangan Mahasiswa dan Faktor-faktor yang Mempengaruhinya. Proceedings of The 4th Internasional Conference on Teacher Education; Join Conference UPI \& UPSI. Bandung.

Krishnakumar, R dan Vijayakumar, L. 2013. Financial Inclusion : A Demographic Perspective. International Journal of Current Research. Vol. 5, Issue, 12, pp.3835-3837, December, 2013. 
Nasution LN, Sari PB, Dwilita H. 2013.

Determinan keuangan inklusif di Sumatera Utara, Indonesia. 14 (1): 58-66.

Otoritas Jasa Keuangan. 2016. Survei Nasional Literasi dan Keuangan Inklusi Keuangan 2016. Jakarta (ID) : OJK.

Nugroho A. 2017. Analisis determinan inklusi keuangan di Indonesia. Skripsi. Semarang : Universitas Diponegoro.

Putro LW, Nainggolan YA. 2016. Investment inclusion among Indonesia online community. Journal of Business and Management. 5(4): 597-603. 